treatment may be of benefit in avoidance of overdose or ineffectiveness and premature withdrawal. Atomoxetine is a selective norepinephrine reuptake inhibitor, approved in 2002 for the treatment of ADHD. The recommended daily dose is $1.2 \mathrm{mg} / \mathrm{kg}$, ranging from $0.5 \mathrm{mg} / \mathrm{kg}$ initial dose to a maximum of $1.8 \mathrm{mg} / \mathrm{kg}$. Unlike the dosage of stimulant medication that is not based closely on body weight, the initial recommended dose of atomoxetine is commonly calculated by weight. The results of the Netherlands study might indicate the need to begin treatment with atomoxetine using the smallest test dose (10 mg daily), with gradual increments based more on early response or side effects than body weight. The cost to a patient of cytochrome P450 2D6 genotyping is quoted by one laboratory at $>\$ 700$; that of CYP450 C19 is slightly greater. The cost-benefit ratio of initial enzyme testing of cytochrome P450 2D6 versus close monitoring of response to carefully graded doses of atomoxetine would require further study. Failed treatment with recommended dose schedules of atomoxetine or early occurrence of side effects should alert clinicians to a probable underlying abnormal cytochrome enzyme activity.

\title{
SERVICE NEEDS OF YOUNG ADULTS WITH ADHD
}

The need for ongoing adult mental health services for young people with attention deficit hyperactivity disorder (ADHD) in the UK was determined by a follow-up study of 102 young people with ADHD who were on medication and treated at a pediatric neurodisability clinic in Sheffield. Over 50\% patients were well controlled, $71 \%$ had at least one comorbid condition, 46 received intervention from child and adolescent mental health services, $17 \%$ had committed criminal offenses, and $37 \%$ were likely to need transition to adult mental health services. Management of ADHD by specialist nurses working with a medical practitioner or adult mental health professional was considered ideal care for young patients transitioning from pediatric to adult clinics. (Taylor N, Fauset A, Harpin V. Young adults with ADHD: an analysis of their service needs on transfer to adult services. Arch Dis Child July 2010;95:513-517). (Respond: Dr Val Harpin, Ryegate Children's Centre, Sheffield Children's Hospital Foundation NHS Trust, Tapton Crescent Road, Sheffield S10 5DD, South Yorkshire, UK. E-mail: val.harpin@sch.nhs.uk).

COMMENT. In the US, treatment of children with chronic neurologic disorders past adolescence and during college often poses problems. The young adult care of myelomeningocele, cerebral palsy and muscular dystrophy is particularly difficult to arrange. ADHD is a lesser problem, but those patients with persisting symptoms as young adults need specialized attention and supervision during the transition period. The nurse practitioner working closely with the pediatrician, pediatric neurologist or child psychiatrist is an ideal person to supervise this transitional care.

\section{TV/Video game exposure and attention deficits in children and young adults.}

A large sample (1323) of middle childhood participants and a smaller sample (210) of late adolescent/early adult participants were assessed during a 13-month period for television and video game exposure. The association of screen media and attention problems was similar across media type (TV or video games) and age (middle childhood or late adolescent/early adult). (Swing EL et al. Pediatrics Aug 2010;126:214-221). 
Environmental factors, in addition to genetic, are important in the cause or exacerbation of ADD.

\section{ATTENTION DEFICIT AND AUDITORY PROCESSING DISORDER}

Auditory processing (AP) skills, cognition (IQ, memory, language, and literacy), and attention (auditory and visual) in 6- to 11-year-old children with normal hearing $(\mathrm{N}=1469)$ were tested in schools in the UK and evaluated by researchers at Medical Research Institute of Hearing Research, Nottingham, UK. AP improved with age. Poorfor-age AP was significantly related to poor cognitive, communication, and speech-innoise performance $(\mathrm{P}<0.001)$. Correlations between auditory perception and cognitive scores were generally low. Response variability in AP tests, reflecting attention, and cognitive scores were the best predictors of listening, communication, and speech-innoise skills. Sympioms of APD were unrelated to auditory sensory processing. APD is primarily an attention problem, and treatment should be directed toward control of attention deficit. (Moore DR, Ferguson MA, Edmondson-Jones AM, Ratib S, Riley A. Nature of auditory processing disorder in children. Pediatrics Aug 2010;126:e382-e390). (Respond: David R Moore PhD, MRC Institute of Hearing Research, University Park, Nottingham NG7 2RD, UK. E-mail: davem@ihr.mrc.ac.uk).

COMMENT. Auditory inattention and reduced cognitive ability are the best predictors of listening problems. "Auditory perception disorder" or "central auditory dysfunction" is a controversial subject and term for children with normal hearing but poor listening skills. The UK researchers prefer a definition based on reduced auditory attention and not a sensory processing problem.

\section{NEONATAL DISORDERS}

\section{MRI AND PREDICTION OF OUTCOME OF HIE}

Published data regarding the prognostic utility of conventional MRI in neonates with hypoxic ischemic encephalopathy are reanalyzed by researchers at University of Oxford, UK. Severe abnormalities on conventional MRI in the first week have a sensitivity of $71 \%$ and specificity of $84 \%$ for very adverse outcome in infants with moderate or Sarnat stage 2 encephalopathy. MR biomarkers alone are not sufficiently accurate to direct treatment-limitation decisions. Limitations in existing prognostic studies include small sample size, selection bias, and overly inclusive outcome assessment. MRI or MR spectroscopy may have a role in combination with other prognostic markers to identify infants with very adverse outcome. Meta-analysis studies do not provide a clear definition of those HIE infants who will have a very severe outcome if they survive. (Wilkinson D. MRI and withdrawal of life support from newborn infants with hypoxic-ischemic encephalopathy. Pediatrics Aug 2010;126:e451e458). (Respond: Dominic Wilkinson MBBS, FRACP, Department of Public Health and Primary Health Care, Ethox Centre, University of Oxford, Headington OX3 7LF, UK. Email: dominic.wilkinson@ethox.ox.ac.uk). 